\title{
Implementation of the EU Directive on the energy performance of buildings in Austria
}

\author{
R. Brandtweiner \& A. Hoeltl \\ Department of Management and Economics, \\ Danube University Krems, Austria
}

\begin{abstract}
According to the Kyoto Protocol the European Union has to reduce its greenhouse gas emissions by 8\% from 1990 levels by 2008-2012. Increased energy efficiency in the building sector holds a great potential to reduce carbon dioxide emissions and, therefore, is an important part of a group of policies and measures necessary to comply with the Kyoto protocol, the European Parliament and the Council of the EU laid down minimum energy performance requirements for buildings in the EU directive on the energy performance of buildings.

The study at hand aims at developing recommendations for the implementation of the EU directive on the energy performance of buildings in Austria. The objective of an Austrian resolution has to have an institutional framework. On the one hand, buildings with the lowest emission reduction costs should be thermal-energetic remediated to reach the Kyoto targets in the building sector in the most economically efficient way and, on the other hand, new buildings should meet minimum energy performance requirements considering long-term energetic, ecologic and economic efficiency.
\end{abstract}

Keywords: Kyoto targets, carbon dioxide, EU directive, building sector, energy performance, Austria.

\section{Introduction}

Climate change is now accepted and confirmed by the scientific community and becomes more and more evident particularly by the glacial fusing and natural disasters which have been observed in the last decades. Due to, in part, the feasible and probable economic costs of the man-made climate changes, most of 
the industrial countries have agreed to reduce the greenhouse gas emissions by ratifying the Kyoto protocol.

One of the measures taken by the European Union to reach the Kyoto reduction goal of eight $\%$ is to increase the energy efficiency of buildings, because the housing sector is responsible for nearly $40 \%$ of final energy consumption in the EU. Towards this goal, the EU directive on energy performance of buildings was laid down in 2002. The EU member states should have transposed this directive in national law by 2006.

The EU directive establishes the general principles for a system of energy performance requirements and their objectives; it is restricted to minimum standards. Each member state has to implement the details and is requested to go beyond the minimum requirements of the directive. By the end of 2006 almost none of the member state had transposed the directive entirely in national law, thus the member states make use of the option of an additional period of three years.

This paper questions the reasons for the extensions and investigates the actual state of implementation of the directive in Austria. The existing Austrian implementation plans are analysed and corrective and supplementary recommendations are made for an ecological and economic efficient transposition of the EU directive on the energy performance of buildings.

\section{The EU directive on energy performance of buildings (European Parliament and European Council [3])}

In 2002 the European Parliament and the Council laid down minimum energy performance requirements for buildings and specified criteria for an energy performance certification (directive 2002/91/EC of the European Parliament and of the Council of 16 December 2002 on the energy performance of buildings). The requirements were intended to be transposed by the EU member states by the year 2006. The directive's objectives are to improve the energy performance of buildings within the boundaries of the European Community and to promote these improvements. The directive considers economic aspects including cost effectiveness, demand driven needs like indoor climate requirements, and geographic circumstances such as outdoor climatic and local conditions. The main parts of this directive are the application of minimum requirements on the energy performance of existing and new buildings, energy certification of buildings and regular inspection of boilers and of air-conditioning systems.

\subsection{Minimum requirements on the energy performance}

The EU member states have to adopt a methodology of calculation of the energy performance of buildings. According to this methodology, minimum energy performance requirements for buildings have to be set which distinguish between new and existing buildings and between different categories of buildings.

For new buildings with a total useful floor area over $1,000 \mathrm{~m}^{2}$, there must be additional verifications; for example, one must verify whether decentralised 
energy supply systems based on renewable energy are technically, ecologically and economically feasible.

Only an existing building with a total useful floor area exceeding $1,000 \mathrm{~m}^{2}$, and only if it is going to be substantially renovated, is bound to the minimum requirements.

The directive also lists some categories of buildings such as monuments officially protected, temporary buildings, or buildings used as places of worship, for which the requirements are not applicable.

\subsection{Energy certification of buildings}

Article 2 of the directive defines the energy performance of building as "the amount of energy actually consumed or estimated to meet the different needs associated with a standardised use of the building ... This amount shall be reflected in one or more numeric indicators." The indicators have to be calculated by taking into account certain technical parameters including insulation, solar exposure and others. All of these parameters are listed in the directive and in the annex of the directive.

Article 7 of this directive lays down the regulations concerning the energy performance certificate. Section 1 states that member states have to ensure that such a certificate is made available to the owner and to the prospective buyer or tenant. The validity of the certificate is limited to ten years. Certifications for apartments or units designed for separate use in blocks can be issued based on a certificate of the whole building or on an assessment of a similar apartment in the same block.

Section two of Article 7 says the following: "The energy performance certificate for buildings shall include reference values such as current legal standards and benchmarks in order to make it possible for consumers to compare and asses the energy performance of the building. The certificate shall be accompanied by recommendations for the cost-effective improvement of the energy performance. The objective of the certificates shall be limited to the provision of information and any effects of these certificates in terms of legal proceedings or otherwise shall be decided in accordance with national rules."

The third and last section of Article 7 of the directive deals with the placement of the energy performance certificate in public buildings. It says that all member states should make sure that large buildings (more than $1,000 \mathrm{~m}^{2}$ useful floor area) which are used by public authorities and by other institutions providing public services have an energy certificate which is not older than ten years. Also, the certificate should be placed prominently so that it can be seen by the public easily. Relevant climatic factors such as recommended and current indoor temperature ranges should be clearly displayed.

\subsection{Inspection of boilers, air-conditioning and heating systems}

The EU member states have to adopt the necessary measures to guarantee the regular inspection of boilers of an effective rated output of 20 kilowatts $(\mathrm{kW})$ to $100 \mathrm{~kW}$. A one-off inspection of the whole heating installation is required for 
heating installations with boilers of an effective rated output of more than $20 \mathrm{~kW}$ and which are at least 15 years old. Air-conditioning systems of an effective rated output of more than $12 \mathrm{~kW}$ have to be inspected regularly.

\section{Intended implementation in Austria}

Why is the directive not yet implemented in Austria? The most important reasons are the federalistic regulation; the building regulations and the building subsidies differ in the nine federal states in Austria. Additionally, there exists a jurisdiction conflict between the federal government und the federal states in terms of implementation.

The Austrian Institute of Construction Engineering (Österreichisches Institut für Bautechnik OIB [9,10]) made a recommendation for thermal-energetic minimum requirements for buildings in Austria and also for the transposition of the directive in national law. The requirements differ according to the building category (residential buildings and non-residential buildings), whereby the paper at hand focuses on residential buildings. An important demand of the institute is the standardizing of the building regulations in Austria.

\subsection{Standardizing}

Traditionally, the nine federal states of Austria have different building regulations. Neither the first attempt in 1948 nor the second attempt in the sixties to standardize the regulations was successful. The current attempt to standardize the regulations started in March 2000 and there is a great hope that this attempt will achieve the long desired outcome: standardized building regulations for Austria (Cervinka [2]).

These regulations contain the "core" of the Austrian "building codes", all federal states have to accept them. Standardized building regulations in Austria will have a positive impact on this industry as well because substantial economic barriers are created when regional laws differ in a small country like Austria (o.V. WKO [14]). Finally, fifty years after the first classical attempt to standardize the Austrian building regulations for all nine federal states, the odds for success have never been better (Mikulits [8]).

\subsection{Thermal-energetic requirements}

\subsubsection{New buildings}

New residential buildings are not allowed to exceed a maximum permissible heat demand of $78.0 \mathrm{kwh} / \mathrm{m}^{2} \mathrm{a}$ and as of $2010,66.5 \mathrm{kwh} / \mathrm{m}^{2} \mathrm{a}$, according to the recommendations of the OIB.

The federal states are allowed to vary the requirements of the maximum permissible heat demand depending on the mean degree-days of the location of the building. The specified calculating method also takes into account the climate conditions, which means that a colder climate needs stricter minimum requirements on the energy performance of buildings. 


\subsubsection{Existing buildings}

A substantial renovation is defined either by the renovation costs, which have to exceed $25 \%$ of the total value of the building, or by the dimension of the renovation, which means at least a renovation of $25 \%$ of the building complex.

According to the suggestion of OIB existing buildings only with a total useful floor area over $1000 \mathrm{~m}^{2}$, and only if they are going to be renovated substantially, are bounded to the minimum requirements. They are not allowed to exceed a maximum permissible heat demand of $102.0 \mathrm{kwh} / \mathrm{m}^{2} \mathrm{a}$, from $201087.5 \mathrm{kwh} / \mathrm{m}^{2} \mathrm{a}$. The federal states are again allowed to vary the requirements of the maximum permissible heat demand depending on the mean degree-days of the building place.

Existing buildings which are going to be renovated, but not substantially, have to meet specific thermal characteristics (u-values) of different building components like windows, outer walls, and ceilings. These thermal characteristics are valid for new buildings and existing buildings, renovated substantially, too.

\subsection{The "Energieausweis-Vorlage-Gesetz"}

The Austrian "Energieausweis-Vorlage-Gesetz" which is abbreviated EAVG and simply means "energy performance certificate submission law" is a federal law, therefore it has to be abided by everybody in the nation. In accordance with the EU directive, the EAVG states that, for instance, a seller of a certain building has to provide an energy performance certificate to the buyer. Concretely, this means that the seller has to show the potential buyer the certificate when they start the bargaining negotiations and the seller has to hand over the certificate to the buyer when the contract is settled. This regulation is federal law and, unfortunately, due to the existing structure of laws in Austria, the method used to calculate the energy performance of a building is written under state law, not federal law, i.e. theoretically each of the nine Austrian provincial governments has the right to develop their own calculation methods. This means that Austria could have up to nine different methods of calculating the energy performance of a building and nine different levels of minimum energy performance requirements. National law only states that an energy performance certificate has to exist and that this certificate has to be shown and handed over in certain situations (Popp [12]).

Considering that Austria is a small country, it is quite clear that this situation could lead to difficulties. Furthermore, the possibility that such a small country might have nine different ways of calculating the energy performance of a building makes one not want to think of how many different ways of calculating the energy performance of a building might exist within the boundaries of the EU.

\section{Recommendations for the implementation in Austria}

According to the EU burden sharing, Austria has to reduce its greenhouse gas emissions by $13 \%$. In 1990, the emissions were on a level of 77.64 million tons $\mathrm{CO}_{2}$ equivalent, and they have to be reduced to 67.55 million tons. As in many other EU member states, the $\mathrm{CO}_{2}$ emissions in Austria have not been reduced in 
the last decade, but increased. In Austria they are up to more than 90 million tons, therefore, Austria would have to reduce the greenhouse gas emissions by more than 22 million tons or nearly $25 \%$.

The economic reduction potential of energy in the housing sector is estimated at 25 to $30 \%$. This means that the total Austrian energy consumption could be reduced by about seven \% (on the basis of 1990) and one third of the Kyoto target for Austria could be fulfilled within the housing sector (Hoeltl [5]). Therefore, Austria should take the implementation of the EU directive as a chance to standardize building regulations and to set up minimum standards for the energy performance of buildings which are as energy efficient as they are economically feasible.

In addition to the direct ecological and economical advantages of a better energy performance of buildings, the Austrian economy will also benefit by the increase in employment and the positive growth effects.

The suggested minimum requirements by OIB for 2010 (3.2.1) are, however, already fulfilled for a substantial part of the new buildings today, so these numeric indicators do not have a great future. Furthermore, the methodology of calculation of the energy performance of buildings which will be used for the energy certification of buildings is not strict enough because it was created by using results that are about $8 \mathrm{kwh} / \mathrm{m}^{2}$ a too low (Lang [7]). In our opinion Austria should aim their standards higher than the planned implementation of the EU directive.

\subsection{Recommendations for new buildings}

Due to the uncertainty of energy prices in the future, which may fluctuate greatly, exact calculations are necessary to come up with a value of a maximum permissible heat demand, which is highly energy efficient and still economical profitably. We recommend a value of $50 \mathrm{kwh} / \mathrm{m}^{2}$ a for new buildings which is economically safe value.

The recommended value of 50 means an additional reduction of 16.5 $\mathrm{kwh} / \mathrm{m}^{2} \mathrm{a}$ from the 2010 values $\left(28 \mathrm{kwh} / \mathrm{m}^{2}\right.$ a the years before) and brings a total additional reduction potential of $77,550,000 \mathrm{kwh} / \mathrm{a}$ or $77,550 \mathrm{mwh} / \mathrm{a}$ and thereby, compared to the OIB recommendation of $66.5 \mathrm{kwh} / \mathrm{m}^{2} \mathrm{a}$, an additional $\mathrm{CO}_{2}$ reduction of 11,632.5 tons every year (assumptions: the number of new dwellings completed annually in Austria is about 47,000 with an average useful floor area per dwelling of about $100 \mathrm{~m}^{2}$ and the emission factor per mwh is $0.15)$. If we were to go beyond the value of $50 \mathrm{kwh} / \mathrm{m}^{2}$ a for new buildings, it would be ecological and economical inefficient.

Figure 1 shows the average heat demand in $\mathrm{kwh} / \mathrm{m}^{2} \mathrm{a}$ of the existing buildings, for new buildings under the current building regulations, under the intended and under the recommended implementation.

\subsection{Recommendations for existing buildings}

The potential for energy savings from renovation of the existing buildings is about four million tons $\mathrm{CO}_{2}$ equivalent (ACCC [1]). The renovation of existing 
buildings is high profitably (Getzner [4]), and energy savings up to $67 \%$ are economically feasible.

Under these circumstances, the EU directive and Austria are planning to apply the maximum permissible heat demand only on existing buildings with a total useful floor area over $1,000 \mathrm{~m}^{2}$. This is not extensive enough, because only about $30 \%$ of the total housing stock would be covered in Austria.

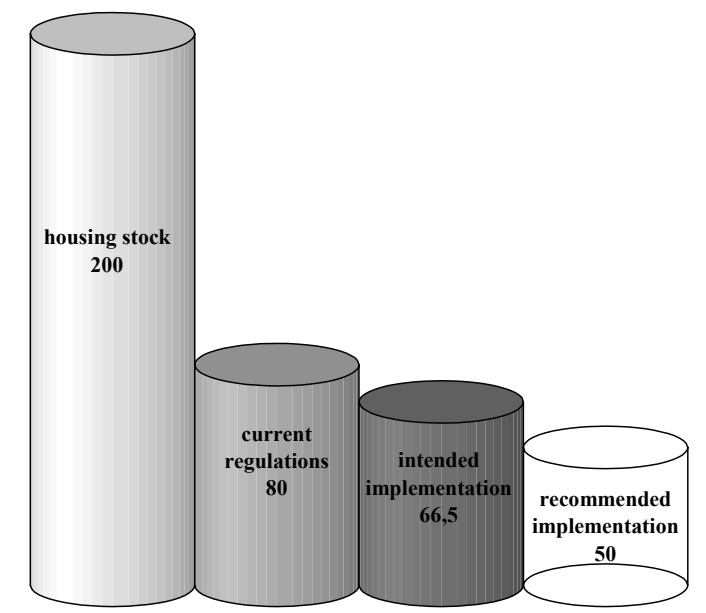

Figure 1: Average heat demand in $\mathrm{kwh} / \mathrm{m}^{2} \mathrm{a}$ of the housing stock, for new buildings under the current building regulations, under the intended implementation of the EU directive and under the recommended implementation.

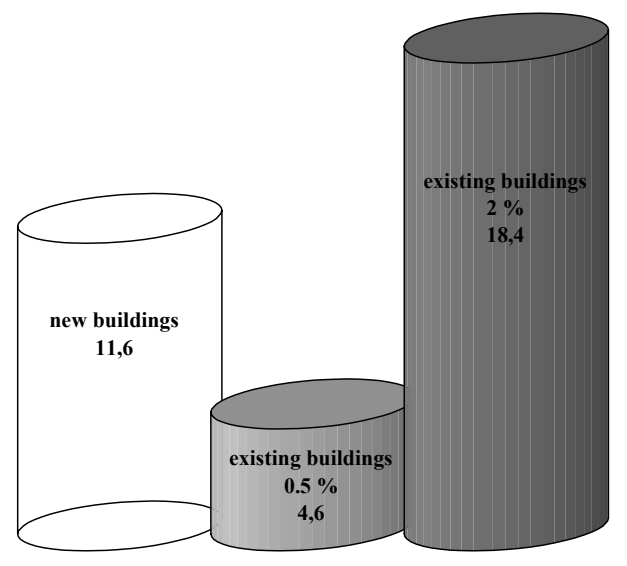

Figure 2: Additional annual reduction of $\mathrm{CO}_{2}$ equivalent in 1,000 tons for new buildings and existing buildings with 0.5 and $2 \%$ renovation rate by the recommended implementation compared to the intended implementation. 
First, it is our recommendation to bind each existing building which is going to be renovated substantially to the minimum requirements and secondly, we recommend that the maximum permissible heat demand be decreased to 67.5 $\mathrm{kwh} / \mathrm{m}^{2} \mathrm{a}$. This value is already exists in state-of-the-art engineering.

The annually renovation rate in Austria is about $0.5 \%$, so each year nearly 17,000 dwellings with an average useful floor area of $90 \mathrm{~m}^{2}$ are renovated. Going below the suggested value of $87.5 \mathrm{kwh} / \mathrm{m}^{2}$ a by OIB means an additional energy saving of 30.6 million $\mathrm{kwh}$ a year, or $30,600 \mathrm{mwh}$ or an additional emission reduction of 4,590 tons $\mathrm{CO}_{2}$ equivalent.

With the actual renovation rate of $0.5 \%$, about $1.500,000 \mathrm{~m}^{2}(17,000$ dwelling times $90 \mathrm{~m}^{2}$ ) are remediated annually. The average heat demand of the existing buildings completed before 1990 is about $200 \mathrm{kwh} / \mathrm{m}^{2} \mathrm{a}$. The binding of each renovation to the minimum requirements means an annual reduction of about $199.500,000 \mathrm{kwh}$ or $199,500 \mathrm{mwh}$ and therefore leads to an annual emissions reduction of 30,000 tons $\mathrm{CO}_{2}$ equivalent.

The renovation rate in Austria is low and should be increased to $2 \%$ per year. If this were the case, the additional annual energy saving based on our recommendation would be $122,400 \mathrm{mwh}$ and the additional $\mathrm{CO}_{2}$ reduction 18,360 tons. The total annual reduction under that renovation rate will be about 800,000 mwh and 120,000 tons $\mathrm{CO}_{2}$ equivalent. Furthermore, the increased renovation rate would mean an increase of the Austrian GDP by $0.4 \%$, and of the employment rate by $0.3 \%$ (Austrian Institute for Economic Research, Österreichisches Institut für Wirtschaftsforschung [11]).

Figure 2 shows the additional annual reduction of $\mathrm{CO}_{2}$ equivalent in 1,000 tons for new buildings and existing buildings with 0.5 and $2 \%$ renovation rate by the recommended implementation compared to the intended implementation.

\subsection{Recommendations for housing subsidies}

Generally, the housing subsidies should increase with better energy performance, as has been already realized in most of the federal states.

In Austria about $80 \%$ of all new built and renovated flats are partly financed through public funding. The renovation of the housing stock receives at the moment 20 to $25 \%$ of these housing subsidies.

In order to use the enormous energy and $\mathrm{CO}_{2}$ reduction potential better in the housing sector, the housing subsidies should be transferred from new buildings to the building renovations. This should be done, on the one hand, to increase the renovation rate and, on the other hand, to give incentives to strive for better energy performance of renovated buildings than is asked for by the minimum requirements.

\subsection{Recommendations for the energy certification of buildings}

As emphasized in chapter 3.3 of this paper, a main problem is that there could exist nine different ways of calculating the energy performance of a building and nine different levels of minimum energy performance requirements. This matter cannot be settled by implementing a federal law because the Austrian 
constitution states that such regulations are the competency of the provincial governments and not the federal government. Therefore, it is necessary and planned that the nine federal states ratify standardized recommendations by OIB. Only when the obligation to issue an energy performance certificate, the calculation method and the minimum energy performance requirements are regulated the same way in all of Austria we can speak of standardized building regulations in respect to energy performance; and only if such a standardized situation is achieved, can the economic potential of unified regulations (e.g. reduced transaction costs) be fully utilized.

\section{Conclusions}

The directive on the energy performance of buildings is a large milestone the European Union has set to reduce greenhouse gas emissions and to fulfil the Kyoto targets because it refers to a sector which represents about $40 \%$ of final energy consumption in the EU and where energy efficiency measures are longterm and sustainably effective.

It is up to the EU member states to lay down the concrete numeric indicators concerning the energy performance of new and existing buildings, distinguishing between different building categories. However, the implementation of the directive by the member states takes place very slowly. It should be done with ecological and economical judgment and conscientiousness, because each new or renovated building with bad energy performance is a new emission source which could have been avoided very cost efficiently and thereby an expensive and lost reduction chance for the next decades.

The largest energy reduction potential and thereby the largest reduction potential for greenhouse gas emissions in the housing sector is to be found in the area of building renovation. Therefore, in addition to the minimum requirements on the energy performance of buildings, existing institutional conditions, current regulations concerning the subsidies in this area and the legal framework (e.g. the rental law) have to be changed to enhance the incentives for building renovation using the highest energy reduction potential possible. Then the large $\mathrm{CO}_{2}$ reduction potential within the housing sector can make an important contribution to the Kyoto targets.

\section{References}

[1] ACCC - Österreichischer Klimabeirat, Das Kyoto-Paket, Wirtschaftliche Innovation durch Klimaschutz, www.accc.gv.at

[2] Cervinka, T., Eine für Alle - lautet das Ziel, 14.11.2005, http://www.bauforum.at/ireds-12652.html

[3] European Parliament and European Council, Directive 2002/91/EC of the European Parliament and the Council of 16 December 2002 on the energy performance of buildings. eur-lex.europa.eu 
[4] Getzner, M., Rentabilität der Wärmedämmung und des Kesseltausches eines durchschnittlichen österreichischen Musterhauses mit ausschließlicher Darlehensfinanzierung, Endbericht, Klagenfurt, 2002.

[5] Hoeltl, A., Incentive policy in the area of the housing market for the implementation of the Kyoto targets: the case of Austria, Ecosystems and Sustainable Development V, pp. 375-384, 2005.

[6] Kammerhofer, K., Ferle, A., Köppl, M., Wege zur Steigerung des Bauvolumens um $500 \%$ bei standardisierter thermischer Althaussanierung, Bericht aus Energie- und Umweltforschung, 24/2005, 2005.

[7] Lang, G., 1000 Passivhäuser in Österreich. Passivhaus Objektdatenbank, Berichte aus Energie und Umweltforschung, 6/2004, 2004.

[8] Mikulits, R., Konkrete Schritte zur Harmonisierung der technischen Bauvorschriften, $\quad$ www.iswb.at/forschung/Wbfoe/2001/2001$1 \_$Mikulits.pdf

[9] Österreichisches Institut für Bautechnik, Erläuternde Bemerkungen zur OIB-Richtlinie 6: Energieeinsparung und Wärmeschutz, Wien, 2006.

[10] Österreichisches Institut für Bautechnik, OIB-Richtlinie 6: Energieeinsparung und Wärmeschutz, Wien, 2006.

[11] Österreichisches Institut für Wirtschaftsforschung, Makroökonomische Wirkungen energiesparender Wohnhaussanierungsinvestitionen, Wien, 2002.

[12] Popp, K., Das Energieausweis-Vorlage-Gsetz (EAVG), energy Zeitschrift der österreichischen Energieagentur, 3/2006, pp. 31-32, 2006.

[13] Statistik Austria, Wohnungen 2005, Ergebnisse der Wohnungserhebung im Mikrozensus, Wien, 2006.

[14] WKO, Harmonisierung der Bautechnischen Vorschriften, Rubrik Wirtschaftsrecht, http://portal.wko.at/ 